\title{
Second-Harmonic Generation Imaging of Medieval Human Bone
}

\author{
Thomas B and Taylor S* \\ Mass Spectrometry Research Group, University of Liverpool, UK
}

Submission: October 06, 2017; Published: November 14, 2017

*Corresponding author: Taylor S, Mass Spectrometry Research Group, University of Liverpool, UK, Tel: 0151-794-4517; Fax: 0151-794-4540;

Email: s.taylor@liv.ac.uk

Keywords: Second-harmonic generation; Imaging; Collagen; Medieval bone

\section{Short Communication}

Second-harmonic generation (SHG) imaging using confocal laser microscopy has found use in biomedical investigations as a non-destructive and efficient means to examine collagen structures in animal tissues including bone [1]. The technique takes advantage of an inherent capacity for the large and highly organized coiled coil structure of collagen to absorb two low frequency (low energy) photons and re-emit them as a single photon with twice the frequency but half the wavelength. It thus permits visualizations of microscopic characteristics of collagen in tissues without adding fluorophores. However, SHG has not to our knowledge been applied to ancient bones.
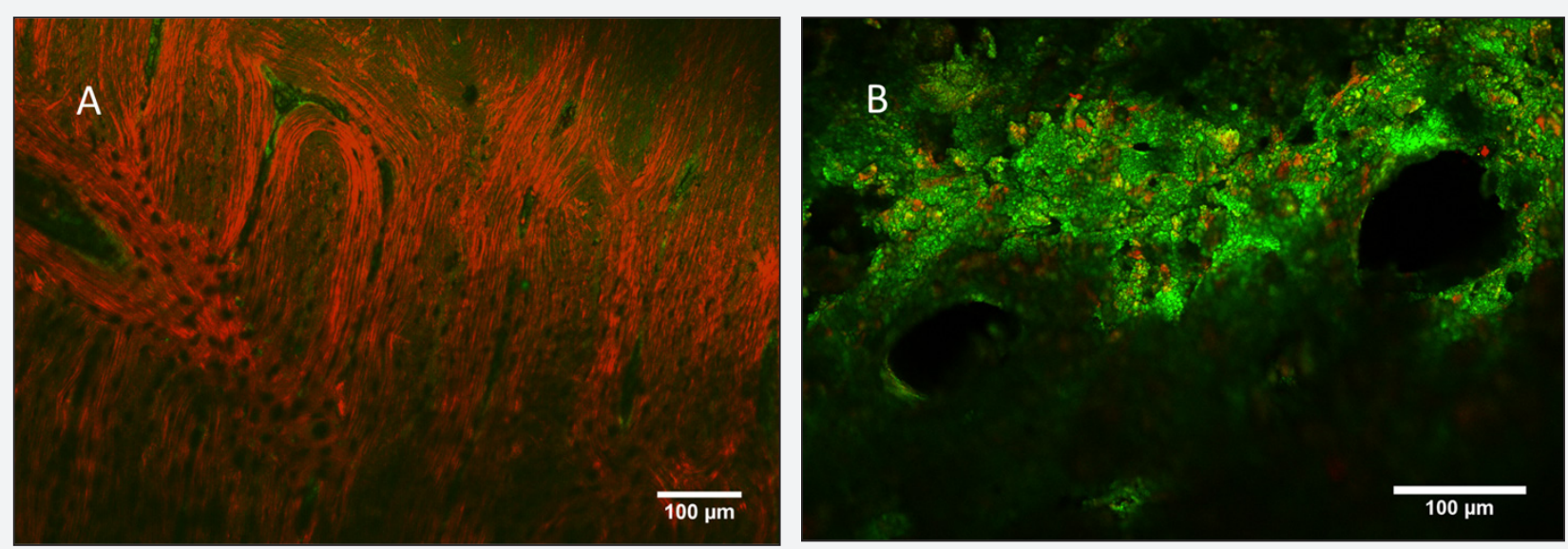

Figure 1: SHG Images of modern and ancient bone. 1A) Red SHG areas represent abundant bone collagen. Collagen striations encircle typical osteocyte structure of modern bovine cortical bone cross-section. Green areas show autofluorescent biomolecules. 1B) Medieval human left ulna cortical bone cross-section from Norton Priory (NP 71_12_9), UK, show greatly diminished collagen signals in red as expected from postmortem collagen decay.

Various techniques have revealed information about burial history and ancient life found in the collagen fraction of ancient bones. For example, workers use collagen extracts for most radiocarbon dating of bones. Stable isotopes in collagen reveal clues about paleodiets, collagen sequencing by tandem mass spectrometry enables interspecies cladistics analyses [2], and weight percent of residual collagen in ancient bone reflects age and burial dynamics [3]. Further, the growing field of molecular paleontology continues to benefit from new techniques that show particular sensitivity to trace amounts of collagen protein
[4]. SHG imaging therefore holds potential to visualize collagenous remnants in ancient bone. Further, digital imaging software can mine images for trends, for example to estimate collagen content in bone.

SHG imaging of cross-sections of cortical bone from a modern bovine femur and a Medieval human left ulna (NP 71_12_9) excavated at Norton Priory, UK, was performed using a twophoton laser scanning confocal microscope outfitted for secondharmonic generation imaging. We used a Zeiss Plan-Apochromat 
10X, NA $=0.45$ objective lens and a 920nm titanium: sapphire laser with power at the specimen of approximately $13 \mathrm{~mW}$ for excitation. A band-pass filter from 420 to $480 \mathrm{~nm}$ was used to collect SHG emissions, and a 500 to $550 \mathrm{~nm}$ filter to collect auto fluorescent emissions in parallel. The SHG emission signal was collected at $458 \mathrm{~nm}$ and autofluorescent signal was collected at $760 \mathrm{~nm}$ using a dual channel Zeiss LSM BiG detector. Auto fluorescence reveals cellular components that include various lipo-pigments and vitamin derivatives as well as aromatic amino acids. Focal planes and bone regions were selected to include sufficient collagen to visualize within the viewing frame. Figure 1 shows composite images of modern an ancient bone with SHG in red and auto fluorescence in green.

Figure $1 \mathrm{~A}$ shows modern bovine femur with a red (collagen) channel intensity threshold of 0-50, and a green channel intensity threshold of 0 to 75 . The intensity thresholds were reversed for each channel in Figure $1 \mathrm{~B}$ ( $\mathrm{red}=0$ to 75 ; green $=0$ to 50 ) in order to enhance the faint collagen signal in the ancient sample.

Table 1: Collagen area ratio estimates for modern and medieval bone.

\begin{tabular}{|c|c|c|c|}
\hline & $\begin{array}{c}\text { SHG Area } \\
\text { (pixels) }\end{array}$ & $\begin{array}{c}\text { Organic Area } \\
\text { (pixels) }\end{array}$ & CAR \\
\hline Modern bovine & 335435 & 338826 & 99 \\
\hline NP 71_12_9 & 212917 & 302510 & 70.38 \\
\hline
\end{tabular}

A Collagen Area Ratio (CAR) from each image was calculated according to Chiu et al. [5] using Fiji [6]. Briefly, CAR =(SHG area of collagen $\div$ total organic area)x100. Red SHG plus green autofluorescence channels were combined to estimate total organic area. Areas shown in Table 1 represent averages of three images each. Future studies will likely specify alternative means of estimating collagen content that serve particular research interests, but CAR is used here to illustrate the potential of processing SHG images. Table 1 compares the average of three CAR calculations each from modern bovine and medieval human ulna NP 71_12_9. The result numerically confirms a decrease in collagen content over time that the decrease in red (collagen) signal in Figure 1 suggests.
CAR calculations of a statistically significant number of firmly dated bone samples could be used to generate collagen decay curves that investigate preservation potentials of various taxa and environments. SHG Imaging visualizes the extent and distribution of collagen fragments in Medieval bone, and image processing software can mine those images to address research questions such as collagen decay in certain taxa or settings.

\section{Acknowledgement}

The authors would like to acknowledge provision of samples of medieval bone from Norton Priory Museum Trust Ltd (NPMT Runcorn, UK) and access to SHG facilities at the University of Texas Southwestern Medical center (UTS, Dallas, USA).The authors would like to thank colleagues at the Department of Electrical Engineering and Electronics at the University of Liverpool: David McIntosh and Tom Fildes for helpful assistance. The authors acknowledge Professor Kate Luby-Phelps (UTS), MsLynn Smith and Dr Frank Hargrave (NPMT) for useful discussions. We have no conflict of interest to declare.

\section{References}

1. Ambekar R, Chittenden M, Jasiuk I, Toussaint KC (2012) Quantitative second-harmonic generation microscopy for imaging porcine cortical bone: Comparison to SEM and its potential to investigate age-related changes. Bone 50(3): 643-650.

2. Asara JM, Schweitzer MH, Freimark LM, Phillips M (2007) Protein sequences from mastodon and Tyrannosaurus Rex revealed by mass spectrometry. Science 316(5822): 280-285.

3. Buckley M, Collins MJ (2011) Collagen survival and its use for species identification in holocene-lower pleistocene bone fragments from british archaeological and paleontological sites. Antiqua 1(1): 1-7.

4. Lee YC, Chiang CC, Huang PY, Chung CY, Huang TD, et al. (2017) Evidence of preserved collagen in an early Jurassic sauropodomorph dinosaur revealed by synchrotron FTIR microspectroscopy. Nat Comm 8: 14220 .

5. Chiu YW, Lo MT, Tsai MR, Chang YC, Hsu RB, et al. (2010) Applying Harmonic optical microscopy for spatial alignment of atrial collagen fibers. PLOS ONE 5: e13917.

6. Schindelin J, Arganda CI, Frise E, Kaynig V, Longair M, et al. (2012) Fiji: an open-source platform for biological-image analysis. Nat Meth 9(7): 676-682.
Your next submission with Juniper Publishers will reach you the below assets

- Quality Editorial service

- Swift Peer Review

- Reprints availability

- E-prints Service

- Manuscript Podcast for convenient understanding

- Global attainment for your research

- Manuscript accessibility in different formats

( Pdf, E-pub, Full Text, Audio)

- Unceasing customer service

Track the below URL for one-step submission https://juniperpublishers.com/online-submission.php 